\title{
ТРЕХМЕРНАЯ ВИЗУАЛИЗАЦИЯ НЕБЛАГОПРИЯТНЫХ ПРИРОДНЫХ УСЛОВИЙ ДЛЯ КОРРЕКТИРОВКИ КАДАСТРОВОЙ СТОИМОСТИ ЗЕМЕЛЬ
}

\author{
Аврунев Евгений Ильич',
} avrynev_ei@ngs.ru

Гатина Наталия Владимировна², www.tusia.0122@mail.ru

\author{
Козина Мария Викторовна², \\ marijamkozina@gmail.com

Актуальность работы обусловлена тем, что достоверность и качество результатов кадастровой оценки земель имеет важное значение как в теоретическом плане, так и в практической деятельности. Современные процессы реформирования системы кадастровой оценки земель должны быть направлены на обеспечение интеграции пространственных данных, получаемых из различных источников, для определения факторов кадастровой стоимости, характеризующих внешнюю среду земельного участка для кадастровой оценки земель населенных пунктов.

Цель: предложить учет инженерно-геологических факторов при кадастровой оценке земель с помощью геоинформационного анализа и трехмерного-картографического моделирования процессов подтопления в границах урбанизированных территорий. Методы: теоретический анализ изучения и обобщения, а также иные общепринятые аналитические методы, геоинформационный анализ, методы картографической визуализации данных, 3D моделирование геопространственных данных.

Результаты. На примере территории Левобережья г. Томска проведен геоинформационный анализ по данным инженерно-геологических изысканий и результатам мониторинга весеннего половодья. Результатом анализа стала электронная карта районирования территории Левобережья по категории сложности инженерно-геологических условий. В результате обоснования необходимости комплексного подхода к определению факторов стоимости для кадастровой оценки земель с учетом влияния неблагоприятных инженерно-геологических и геологических процессов и явлений была построена трехмерная цифровая модель рельефа и геологического строения территории Левобережья. Сиспользованием предложенной модели можно решать научно-практических задачи, связанные с учетом инженерно-геологических факторов для кадастровой оценки земель, ведения единого государственного реестра недвижимости, обеспечения градостроительной деятельности и управления территориальным образованием. Таким образом, предложен подход к оценке неблагоприятных инженерно-геологических и геологических процессов и явлений для корректировки кадастровой стоимости на урбанизированных территориях.

\section{Ключевые слова:}

Кадастровая оценка, урбанизированные территории, геоинформационный анализ, трехмерное моделирование, инженерно-геологические факторы.

\section{Введение}

Мировые информационные технологии начали активно развиваться еще в начале $90-\mathbf{x}$ гг. XX в. В тот период были сформированы все необходимые условия для перехода к новому этапу развития и организации механизмов управления пространственными данными. Такому переходу способствовал накопленный почти за 30-летний период опыт освоения, внедрения и широкого использования геоинформационных технологий. Так были получены первые экспериментальные инфраструктуры пространственных данных. [1]. Таким образом, национальная инфраструктура пространственных данных была создана в Америке, Австралии и в большинстве европейских стран.

В 2006 г. Правительством РФ была разработана и одобрена концепция по созданию и развитию инфраструктуры пространственных данных стра- ны, которая позволила законодательно развивать аналогичные отечественные работы. Главной целью разработки и совершенствования инфраструктуры пространственных данных страны стало повышение качества и эффективности системы государственного управления по средствам использования достоверных оперативных и актуальных пространственных данных на всех уровнях власти для принятия управленческих решений. В 2017 г. Правительством Российской Федерации была разработана и утверждена программа [2] по созданию условий для перехода страны к цифровой экономике, где важную роль играют пространственные данные. Хотелось бы коснуться отдельных задач, стоящих в развитии цифровой экономики, касающихся пространственных данных. В настоящее время в России многие органы исполнительной власти создают и используют пространственные 
данные. Таким примером служат федеральные информационные системы, такие как Единый государственный реестр недвижимости, который публикует пространственные данные об объектах недвижимости по средствам Публичной кадастровой карты. А примером муниципальных информационных систем является информационная система обеспечения градостроительной деятельности (ИСОГД). ИСОГД Муниципального образования «Город Томск» обеспечивает свободный доступ к базовым пространственным данным через сервисы в сети Интернет в режиме on-line.

Подобная информация крайне востребована и создает условия для формирования благоприятного инвестиционного климата в муниципальных образованиях. В области учета земель и развития современного института оценки земель РФ также важны механизмы интеграции и совместное использование пространственных данных.

Современная методика кадастровой оценки земель населенных пунктов, теория и практика которой до сих пор является проблемной задачей $[3,4]$, не учитывает целый ряд природных условий, в которых функционируют объекты недвижимости, в том числе неблагоприятные инженерно-геологические и геологические процессы и явления. Современные процессы реформирования системы кадастровой оценки земель должны быть направлены на обеспечение интеграции пространственных данных, получаемых из различных источников, для определения факторов кадастровой стоимости, характеризующих внешнюю среду земельного участка для кадастровой оценки земель населенных пунктов. В современных условиях используемые данные об объектах оценки, о состоянии рынка недвижимости и о факторах, оказывающих влияние на формирование кадастровой стоимости объекта недвижимости, несопоставимы и не скоординированы между собой в едином геопространстве, что исключает их совместное и комплексное использование.

Результатом чего стало отсутствие единого информационного пространства обо всех элементах городского пространства и природных условиях, которые оказывают существенное влияние на условия землепользования, а следовательно, на стоимость земельных участков.

\section{Неблагоприятные природные условия}

Современные процессы по «цифровизации» России определяют первоочередное развитие геоинформационных технологий и использование пространственных данных, поскольку без актуальных и точных знаний о территории, ее природных особенностях и рельефе невозможно устойчивое экономическое и социальное развитие.

Согласно принципам государственной политики, в отношении рассматриваемого аспекта развитие такой инфраструктуры способствует созданию условий для повышения конкурентоспособности регионов, в том числе и решению вопросов социального развития.
Так, в Стратегии социально-экономического развития РФ, Томской области [5] и других регионов большое внимание уделяется повышению уровня и качества жизни населения, в том числе сбалансированному территориальному развитию. Уровень жизни населения является материальной основой качества жизни, который определяется совокупностью условий человеческого существования. $K$ таким условиям в первую очередь необходимо отнести уровень развития социальной и транспортной инфраструктуры, включающий жилой фонд, объекты социально-бытового обслуживания, степень обеспеченности современными удобствами, уровень благоустройства территории, наличие объектов инженерной инфраструктуры, образования, здравоохранения, культуры, отдыха и др.

Таким образом, можно сделать вывод, что показатели уровня и качества жизни населения призваны раскрывать и определять степень развития социально-экономических отношений. Благоприятные условия для жизнедеятельности населения обеспечивают социально-экономическое развитие образований, тем самым способствуют развитию человеческого капитала и повышению конкурентоспособности регионов и муниципальных образований.

В последнее время в связи с возрастающей инженерно-хозяйственной деятельностью человека возникают в геологической среде неблагоприятные процессы и явления, такие как оползни, землетрясения, карст, сели и др.

Количество таких негативных природных процессов и явлений на территории РФ возрастает. К примеру, оползнеопасные районы занимают около 40 \% площади России и развиваются на территории 725 городов. А эрозионные процессы в настоящее время развиваются на $56 \%$ площади сельхозугодий РФ.

По данным Росгидромета в России происходит 40-70 крупных наводнений ежегодно [6]. В результате неблагоприятным природным процессам и явлениям подвержены сотни городов, десятки тысяч населенных пунктов, а также более 7 млн га сельскохозяйственных угодий.

Последствия от наводнений экспертами оцениваются в 40 млрд р. (в том числе в бассейнах рек Амур, Обь, Терек, Дон, Кубань, Лена, Волга, и прочих).

Ежегодно в России на крупных реках возникают паводки. В результате проведенного исследования Всероссийским научно-исследовательским институтом гидрометеорологической информации Мировым центром данных (ФГБУ «ВНИИГМИМЦД»), было установлено, что общее число опасных гидрологических явлений (наводнений, паводков и селей) в России за первое десятилетие XXI в. с 1990 г. выросло в 1,5 раза.

Таким образом, комфортность проживания определяется совокупностью различных факторов, ключевыми из которых являются инженерногеологические. Следовательно, кадастровая стои- 
мость объектов недвижимости также должна зависеть от уровня комфортности [7-10], в том числе от наличия неблагоприятных инженерно-геологических и геологических процессов и явлений, так как землепользователи и землевладельцы несут затраты, связанные с предупреждением и ликвидацией их последствий.

Такая взаимосвязанность должна быть учтена при определение кадастровой стоимости и расчете налога на недвижимое имущество. В интересах эффективности проведения кадастровой оценки земель и создания эффективной кадастровой системы для определения инженерно-геологических факторов кадастровой стоимости предлагается создание электронных карт населенных пунктов, в которых проводилось бы районирование территории по категориям сложности инженерно-геологических условий на основании определенных границ распространения неблагоприятных инженерно-геологических и геологических процессов и явлений.

В настоящее время разработано достаточно много классификаций неблагоприятных инженерно-геологических и геологических процессов и явлений. Для решения задач научного-обоснованного подхода определения кадастровой стоимости земель населенных пунктов предлагается использовать классификацию В.Д. Ломтадзе, представленную на рис. 1.
Создание электронной карты населенного пункта и его районирование по категориям сложности инженерно-геологических условий и их оценки представляется возможным и более эффективным с использованием геоинформационного анализа и трехмерных геопространственных данных [11-14]. Такой подход позволит получать актуальные сведения об инженерно-геологических факторах для их учета при кадастровой оценке земель населенных пунктов.

Кадастровая оценка земель населенных пунктов должна рассматриваться как система, обеспечивающая комплексное исследование влияния социальных, экологических и экономических факторов, способствующая оптимизации и формированию адаптационной информационной модели земельных ресурсов города в условиях интенсивного антропогенного воздействия. Важность научнообоснованного определения кадастровой стоимости обусловлена тем, что размер платежей за земельные участки в соответствии с действующим законодательством определяется исходя из их кадастровой стоимости.

\section{Геоинформационный анализ}

урбанизированной территории

В течении последних десятилетий на территории г. Томска были проведены многочисленные исследования геологических, инженерно-геологи-

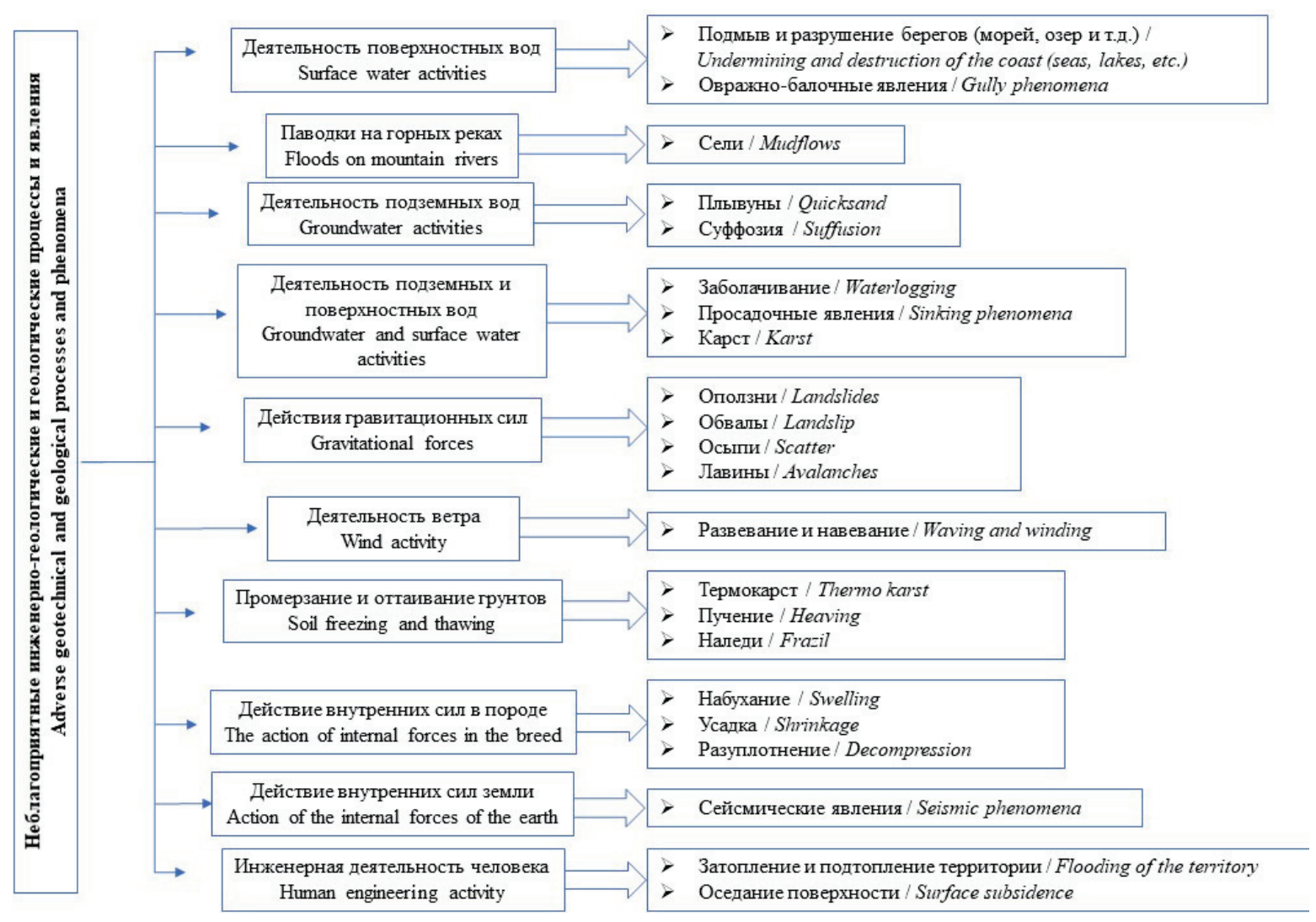

Pис. 1. Классификация неблагоприятных инженерно-геологических игеологических процессов и явлений по В.Д. Ломтадзе

Fig. 1. Classification of adverse geotechnical and geological processes and phenomena according to V.D. Lomtadze 
ческих физико-географических, гидрологических и гидрогеологических условий (В.Е. Ольховатенко, М.Г. Рутман, В.М. Лазарев, Л.А. Строкова, В.К. Попов, О.Д. Лукашевич, В.А. Коробкин, О.Г. Савичев, Е.М. Дутова, А.В. Леонова, В.Д. Покровский и др. [15-21]). В результате был накоплен большой объем данных, характеризующих развитие различных негативных физико-геологических процессов и явлений изучаемой территории. Таким образом определено, что на территории города достаточно активно проявляются неблагоприятные инженерно-геологические и геологические процессы и явления.

Одной из таких территорий города является территория Левобережья. В период весеннего половодья, обильных дождей в осенне-летний период пониженные части рельефа подвергаются подтоплению. Сельские поселения Тимирязево, Дзержинское, Эушта, Нижний склад, Заречный, расположенные на рассматриваемой территории в 2004 г. получили статус городского округа и были включены в границы города Томска. Территория Левобережья обладает достаточно высоким потенциалом для планировочного развития и является перспективным направлением развития города. В геоморфологическом отношении Левобережье расположено в долине р. Томи, приурочено к левобережной пойме, а также является частью ландшафта Обь-Томского междуречья, в границах которого эксплуатируется Томский подземный водозабор. Большая часть поймы реки Томи, в том чи- сле и территория Левобережья, подвержена затоплению в период весеннего половодья. Часть территории занята садоводческими товариществами. Сегодня рассматриваемая территория начинает активно застраиваться.

В связи с этим возникает необходимость определения объективных инженерно-геологических факторов, оказывающих влияние на эффективность землепользования и на кадастровую стоимость земельных участков [22].

Для проведения геоинформационного анализа [23-27] рассматриваемой территории были использованы результаты дистанционного зондирования и моделирования прохождения паводка в г. Томске [28] и возможные границы затапливаемых территорий (рис. 2, a), для разных отметок уровня паводковых вод выполненные ИТЦ «СКАНЭКС» (г. Москва) совместно с МЧС и Администрацией г. Томска. А также результаты инженерно-геологических изысканий (рис. 2, б), выполненных отделом изысканий 000 «Проектно-изыскательский институт транспортной инфраструктуры «Индор-Проект»» и отделом изысканий Филиала ОАО «НИКИМТ-Атомстрой» ТПИИ ВНИПИЭТ.

Для объединения и совместной обработки таких данных и выполнения работ по районированию территории Левобережья по категории сложности инженерно-геологических условий нами был разработан геоинформационный проект в среде QGIS.

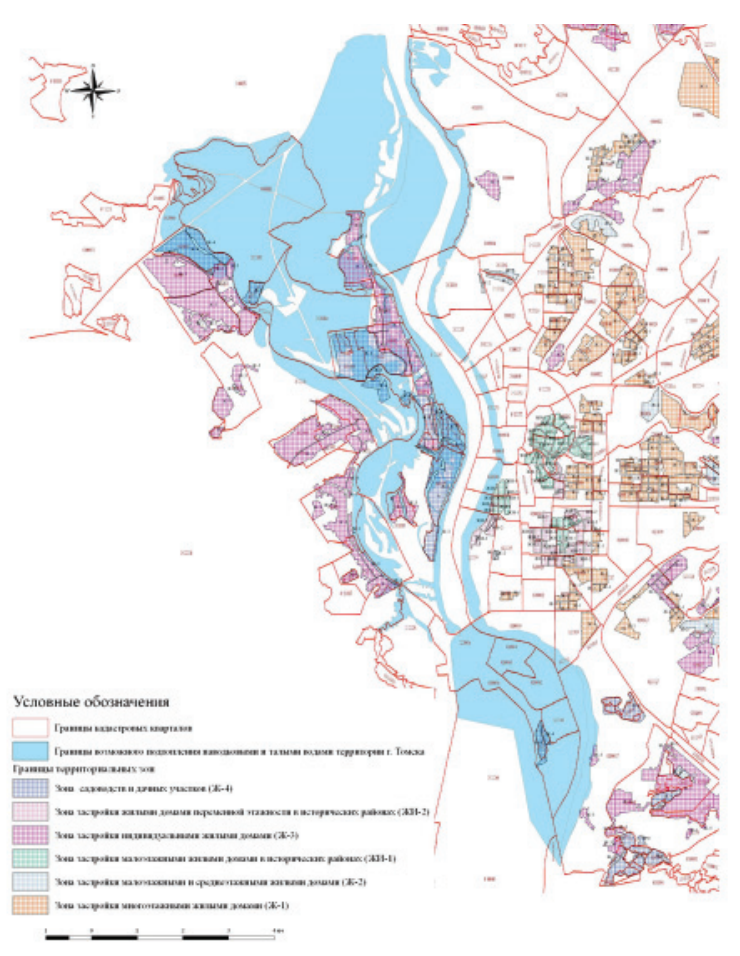

$a / a$

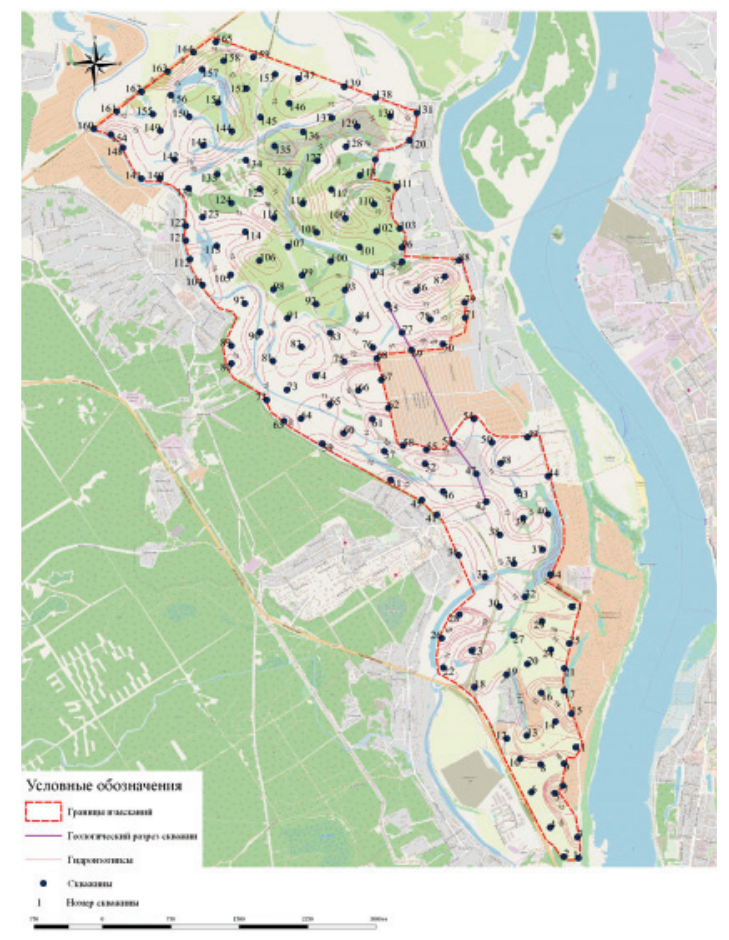

$\sigma / b$

Pис. 2. а) Кадастровый план территории г. Томска с отображениел грании зон возможного затопления паводковыли и тальли вода ми; б) карта гидроизогипс

Fig. 2. a) Cadastral plan of Tomsk territory imaging the boundaries of possible floodwater and meltwater flooding zones; $b$ ) depth to water map 
Таблица. Характеристика природных условий территорий по категории сложности инженерно-геологических условий

Table. $\quad$ Specification of environmental and planning circumstances according to the category of complexity of engineering and geological conditions

\begin{tabular}{|c|c|c|c|}
\hline \multirow{2}{*}{$\begin{array}{c}\text { Инженерно-геологические } \\
\text { факторы } \\
\text { Geotechnical factors }\end{array}$} & \multicolumn{3}{|c|}{$\begin{array}{l}\text { Категория сложности инженерно-геологических условий } \\
\text { Category of complexity of engineering geological conditions }\end{array}$} \\
\hline & I (простая)/(simple) & II (средняя)/(average) & III (сложная)/(complex) \\
\hline $\begin{array}{c}\text { Глубина залегания безнапор- } \\
\text { ных водоносных горизонтов, м } \\
\text { Depth of unconfined aquifers, m }\end{array}$ & $>4$ & $2-4$ & $<2$ \\
\hline $\begin{array}{c}\text { Затопляемость } \\
\text { (обеспеченность, \%) } \\
\text { Flooding } \\
\text { (security, \%) }\end{array}$ & $\begin{array}{c}\text { один раз в } 100 \text { лет } \\
(1 \%) \\
\text { once in } 100 \text { years } \\
(1 \%)\end{array}$ & $\begin{array}{l}\text { между линиями затопления, повторяющимися один раз в } 100 \text { лет } \\
(1 \%) \text { и один раз в } 25 \text { лет (4 \%) с наивысшим горизонтом высоких } \\
\text { вод не более } 0,6 \text { м } \\
\text { between the lines of flooding, repeating once every } 100 \text { years }(1 \%) \\
\text { and once every } 25 \text { years ( } 4 \% \text { ) with the highest horizon of high wa- } \\
\text { ters not more than } 0,6 \text { m above ground level }\end{array}$ & $\begin{array}{c}\text { один раз в } 25 \text { лет и ча- } \\
\text { ще }(\geq 4 \%) \\
\text { once in } 25 \text { years and } \\
\text { more often }(\geq 4 \%)\end{array}$ \\
\hline
\end{tabular}
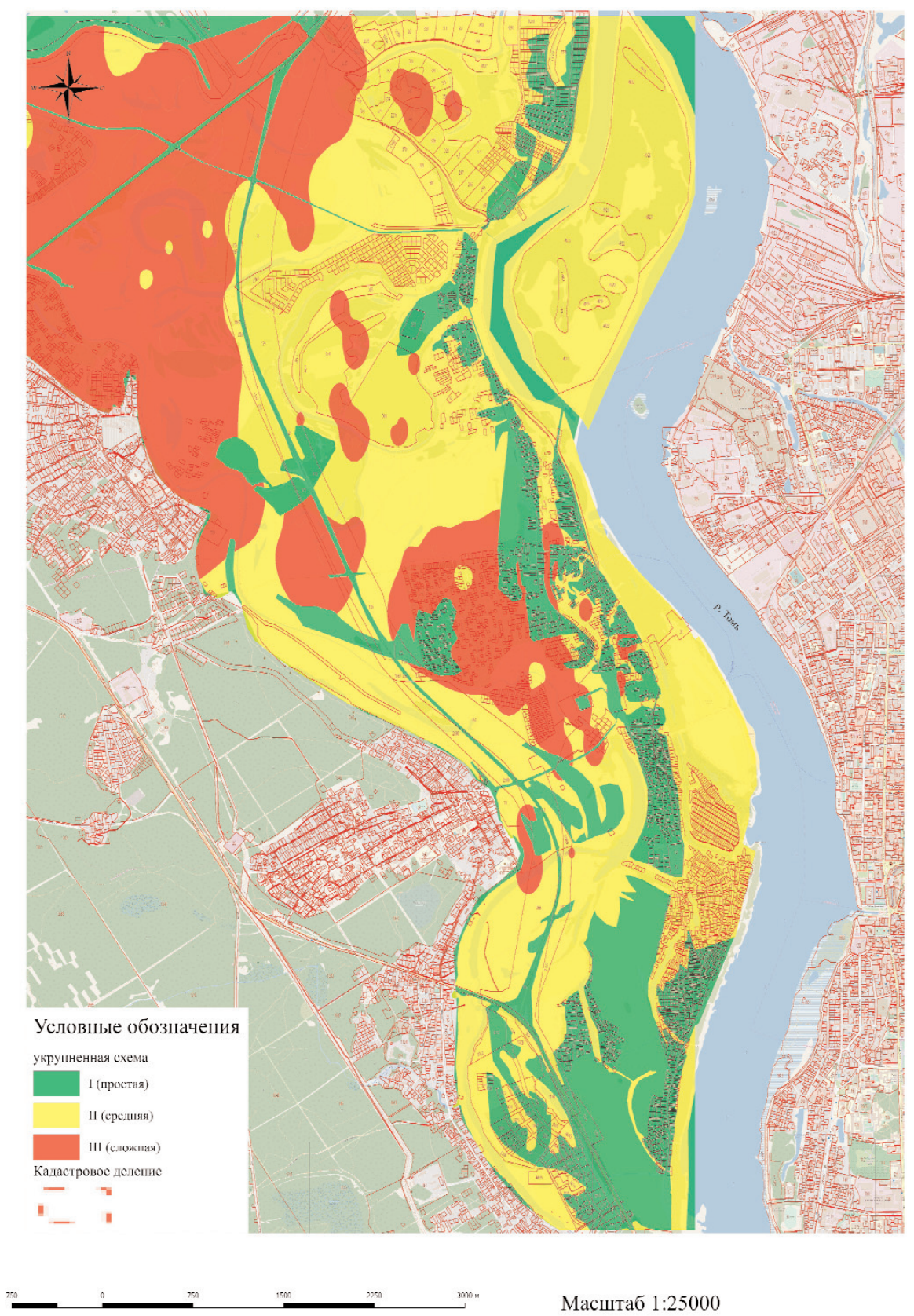

Рис. 3. Электронная карта районирования территории Левобережья по степени сложности инженерно-геологических условий

Fig. 3. Electronic map of zoning Levoberezhye according to the degree of complexity of engineering and geological conditions 
Геологические условия рассматриваемой территории характеризуются наличием грунтовых вод. На данную территорию была составлена карта гидроизогипс, которая показала, что на некоторых участках (в низинах, вблизи поверхностных водоемов и водотоков и др.) положение уровня подземных вод выше критического (в соответствии с СП 11-105-97) (рис. 2, б). Грунтовые воды встречаются на глубине от 1,7 до 7,5 м. Водовмещающими грунтами служат песчаные и гравийно-галечниковые отложения.

Полученная карта положения грунтовых вод была сопоставлена и скоординирована в едином геопространстве с границами зон возможного затопления паводковыми и талыми водами. В результате чего было проведено районирование территории исследования, результатом которого стало выделение трех районов. Характеристика районов по категории сложности инженерно-геологических условий представлена в таблице.
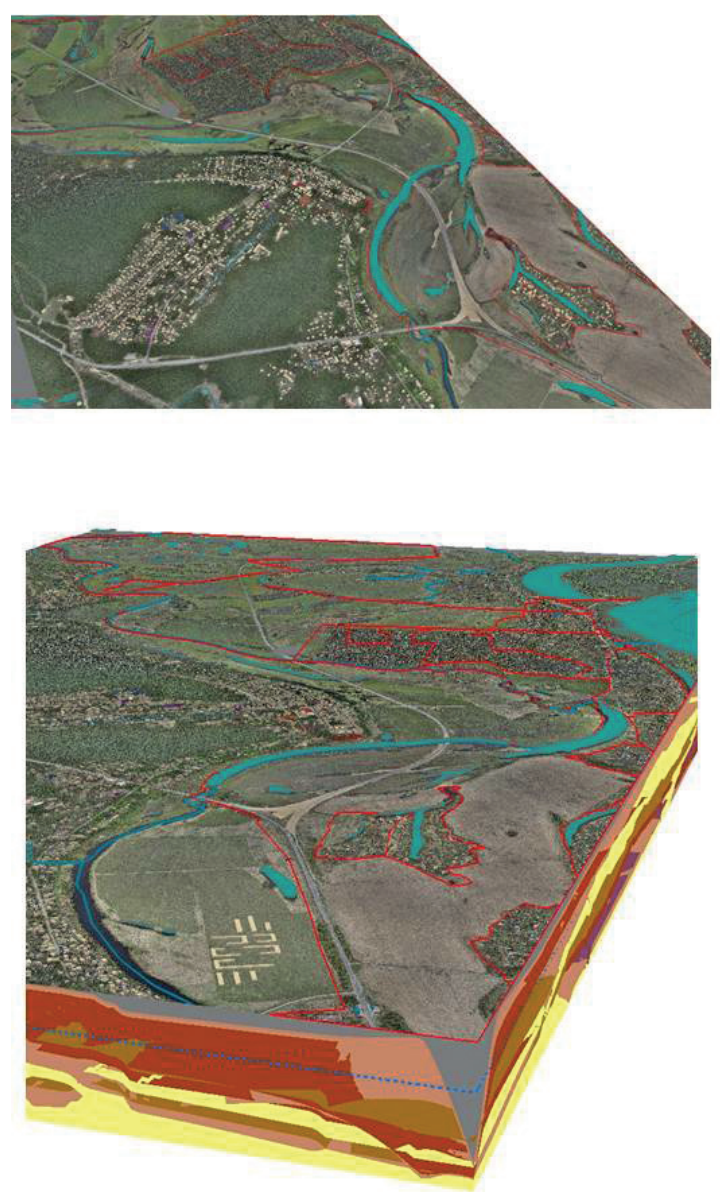

Масштаб

М 1:5000 - по горизонтали

М 1:500 - по вертикали
С помощью применения инструментария «интерполяция» с использованием известных значений глубины залегания грунтовых вод и границ возможного затопления территории для разных отметок уровня паводковых вод (определенных по средствам мониторинга паводковой ситуации [28]) нами была получена электронная карта (рис. 3) с определенными районами, характеризующими неблагоприятные инженерно-геологические и геологические процессы (подтопление, затопление) территории по категории сложности инженерно-геологических условий.

Для анализа условий землепользования территории Левобережья полученное районирование было совмещено с картой кадастрового деления территории и границами территориальных зон, которые имеют определяющее значение.

В результате было определено, что 32 \% площади территории зоны $\Re-4$, в границах которой осуществляется использование земель для садо-

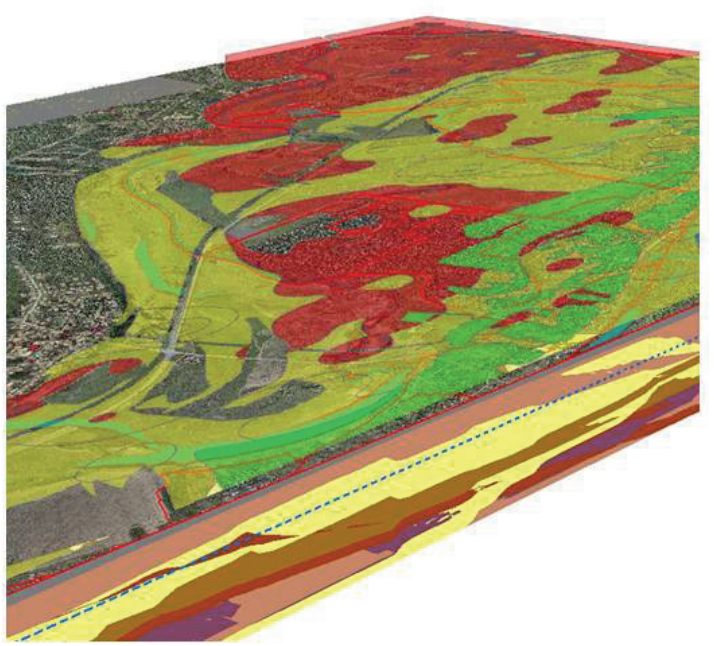

\section{УС.ОВНЫЕ ОБОЗНАЧЕНИЯ}

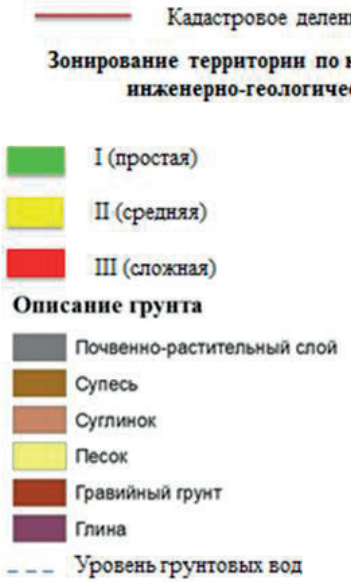

Рис.4. Трехмерная иифровая модель рельефа и геологического строения территории Левобережья: а) с нанесенным на поверхность кадастровым делением территории; б) с нанесенным на поверхность зонированием территории Левобережья по степени сложности инженерно-геологических условий

Fig. 4. 3D digital model of relief and geological constitution of Levoberezhye: a) with marked cadastral area division; $b$ ) with marked zoning of Levoberezhye area according to the degree of complexity of engineering and geological conditions 
водства и огородничества, находится в сложных инженерно-геологических условиях, где уровень грунтовых вод находится на глубине менее 2 м и территория подвержена ежегодному подтоплению. А площадь территориальной зоны Ж-3, которая в основном представлена застройкой индивидуальными жилыми домами, в той же категории сложности составляет 2,6 \% . Вся подтапливаемая территория расположена в границах 28 кадастровых кварталов г. Томска. Полученные результаты означают, что исследуемая территория подвержена распространению неблагоприятных инженерно-геологических и геологических процессов и явлений, которые оказывают значительное влияние на условия землепользования.

\section{D визуализация природных условий территории Левобережья г. Томска}

В результате обоснования необходимости комплексного подхода к проведению факторного анализа для государственной кадастровой оценки земель урбанизированной территории с учетом инженерногеологических факторов была построена трехмерная модель территории Левобережья. Модель реализована в среде ArcGIS и наглядно отображает реальные геологические условия территории и объединяет большое число различных слоев (рис. 4). Поверхность территории представлена ортофотоснимками, выполненными при аэросъемке г. Томска в период 2014-2015 гг. администрацией г. Томска.

Функции 3D-моделирования была реализована в среде ArcGIS с использованием модуля ArcScene. Для создания пространственной модели были построены интерполированные поверхности всех слоев грунта, определенных в результате инженерных изысканий, представленных в виде Grid или TIN поверхностей с разрешением «lyr».

С помощью инструмента «интерполяция» (кригинг) были созданы все имеющиеся поверхности в геологическом разрезе. Далее был использован модуль ArcScene, позволяющий совмещать множество слоев данных в 3D среде. ArcScene полностью интегрирован в среду геообработки, что дает возможность использовать многочисленные аналитические инструменты и функции.

\section{Заключение}

Полученная трехмерная модель позволяет создать максимально точную модель территории и ее геологического строения, которая обладает следующим рядом существенных преимуществ по срав-

\section{СПИСОК ЛИТЕРАТУРЫ}

1. Кошкарев А.В., Ряховский В.М., Серебряков В.А. Инфраструктура распределенной среды хранения, поиска и преобразования пространственных данных / Открытое образование. 2010. - № 5. - C. 61-73.

2. Указ Президента Российской Федерации № 203 от 09.05.2017 г. «0 Стратегии развития информационного общества в Российской Федерации на 2017-2030 годы» / / Собрание законодательства РФ. - 2006. - № 35. - Ст. 3775. нению с моделями, которые используются в настоящее время:

1. Является метрической, построенной в единой системе координат, которая может задаваться пользователем исходя из класса решаемых научно-практических задач (для ведения единого государственного реестра недвижимости, для обеспечения градостроительной деятельности, для управления территориальным образованием). Следовательно, она позволяет определять метрические характеристики объектов недвижимости и их геопространственное положение в территориальном образовании.

2. Позволяет представить результаты инженерногеологических изысканий в более полном и информативном виде и наглядно сопоставить их с условиями землепользования территории, а также с границами земельных участков и кадастрового квартала.

3. С позиций системного подхода позволяет корректировать кадастровую стоимость объектов недвижимости с учетом инженерно-геологических факторов, что необходимо и актуально для создания социально-справедливой и научно-обоснованной налогооблагаемой базы в Российской Федерации.

\section{Выводы}

Такой подход позволяет интегрировать полученные сведения о границах районов различной категории сложности инженерно-геологических условий (неблагоприятных инженерно-геологических и геологических процессов и явлений) в базу данных Единого государственного реестра недвижимости. Эта информация может быть представлена в качестве семантических и графических сведений в раздел дополнительных характеристик о земельных участках для их использования при определении и корректировке кадастровой стоимости земельных участков. Таким образом, предложенная методика визуализации результатов инженерно-геологических изысканий с использованием специализированных программ позволит развить национальную инфраструктуру пространственных данных и даст возможность осуществить интеграцию полученных пространственных данных с данными, содержащимися в государственных информационных ресурсах, что позволит устанавливать научно-обоснованную кадастровую стоимость с учетом инженерно-геологических факторов.

3. Ecologization of water-land property matters on the territory of the Tom lower course / V.K. Popov et al. // IOP Conference Series: Earth and Environmental Science. - V. 33: Contemporary Issues of Hydrogeology, Engineering Geology and Hydrogeoecology in Eurasia. - 2016. - 012057. - 5 p.

4. Попов В.К., Козина М.В. Экологизация кадастровой оценки земель для устойчивого развития урбанизированных территорий // Известия Томского политехнического университета. Инжиниринг георесурсов. - 2015. - Т. 326. - № 11. - С. 98-105. 
5. Стратегия социально-экономического развития Томской области до 2030 года. Приложение к постановлению Законодательной Думы Томской области от 26.03.2015 № 2580. URL: http://old.duma.tomsk.ru/page/29000/ (дата обращения 15.11.2018)

6. Федеральная служба по гидрометеорологии и мониторингу окружающей среды (Росгидромет). URL: http://www.meteorf.ru (дата обращения 15.11.2018).

7. Козочкина Е.А. Совершенствование методического обеспечения кадастровой оценки объектов недвижимости: автореф. дис. ... канд. техн. наук. - Новосибирск, 2018. - 24 с.

8. Попп Е.А. Разработка методики оценки влияния экологической составляющей на кадастровую стоимость земельных участков (на примере города Бийска): автореф. дис. ... канд. техн. наук. - Новосибирск, 2015. - 24 с.

9. Подрядчикова Е.Д. Разработка методики земельно-оценочных работ на основе геоинформационного анализа социально-территориальных взаимосвязей элементов городской инфраструктуры: автореф. дис. ... канд. техн. наук. - Новосибирск, 2015. - 24 c.

10. Кочетова В.А. Кадастровая оценка городских земель на основе учета экологических факторов // Science Time. - 2015. № 12 (24). - С. 422-425.

11. Аврунев Е.И. Технологические аспекты построения 3D-модели инженерных сооружений в городах Арктического региона РФ // Известия Томского политехнического университета. Инжиниринг георесурсов. - 2018. - Т. 329. - № 7. - С. 131-137.

12. Karpik A.P., Avrunev E.I., Truhanov A.E. To the question of geodetic and cartographic provision of cadastral register // International Journal of Applied Engineering Research. - 2015. № 10 (18). - P. 39601-39602.

13. Application of laser scanning for developing a 3D digital model of an open-pit side surface / V.N. Oparin, V.A. Seredovich, V.F. Yushkin, A.V. Ivanov, S.A. Prokopeva // Journal of Mining Science. - 2007. - № 43 (58). - P. 545-554.

14. Ying S., Guo R., Li L. Implementation of 3D cadastre with 3DGIS: Practices and challenges // Journal of Geomatics. - 2018. № 43 (2). - P. 1-6.

15. Ольховатенко В.Е., Рутман М.Г., Лазарев В.М. Опасные природные и техноприродные процессы на территории г. Томска и их влияние на устойчивость природно-технических систем. Томск: Печатная мануфактура, 2005. - 151 с.

16. Строкова Л.А. Инженерно-геологическое районирование территории Томского Приобья по степени устойчивости геологической среды к техногенной нагрузке: автореф. дис. ... канд. наук. - Томск, 1997. - 20 с.

17. Попов В.К., Лукашевич 0.Д., Коробкин В.А. Эколого-экономические аспекты эксплуатации подземных вод Обь-Томского междуречья. - Томск: Изд-во Томского государственного архитектурно-строительного университета, 2003. - $174 \mathrm{c}$.

18. Spatial patterns of the evolution of the chemical composition and discharge of river water in the Ob River basin / O.G. Savichev et al. // Doklady Earth Sciences. - 2016. - V. 466. - Iss. 1. P. 59-63.

19. Hydrogenous mineral neoformations in Tomsk water intake facility from underground sources / E.M. Dutova et al. // IOP Conference Series: Earth and Environmental Science.- V. 33: Contemporary Issues of Hydrogeology, Engineering Geology and Hydrogeoecology in Eurasia. - 2016. - 012017. - 6 p.

20. Geotechnical properties of gullying in Tomsk Oblast / A.V. Leonova et al. // IOP Conference Series: Earth and Environmental Science. - V. 43: Problems of Geology and Subsurface Development. - 2016. $-012037 .-4$ p.

21. Информационно-поисковая система оценки степени подтопляемости территории города Томска / В.Д. Покровский и др. // Вестник Томского государственного архитектурно-строительного университета. - 2015. - № 1 (48). - С. 172-181.

22. Аврунев Е.И., Козина М.В., Попов В.К. Исследование факторов стоимости земель урбанизированных территорий // Вестник Сибирского государственного университета геосистем и технологий. - 2018. - № 2 (23). - С. 130-143.

23. Карпик А.П., Хорошилов В.С. Сущность геоинформационного пространства территорий как единой основы развития государственного кадастра недвижимости // Изв. вузов. Геодезия и аэрофотосъемка. - 2012. - № 2/1. - С. 134-136.

24. Попп Е.А. Геоинформационный анализ влияния экологической составляющей на кадастровую стоимость объектов недвижимости // Инновации и ГИС-технологии для развития территорий: материалы междунар. конф. - Усть-Каменогорск: Восточно-Казахстанский государственный технический университет им. Д. Серикбаева, 2014. - С. 67-74.

25. Karpik A.P., Musikhin I.A. Research and practical trends in geospatial sciences // International Archives of the Photogrammetry, Remote Sensing and Spatial Information. - 2016. - № 41. P. 177-184.

26. Ledoux H., Meijers M. Topologically consistent 3D city models obtained by extrusion // International Journal of Geographical Information Science. - 2011. - № 25 (4). - P. 557-574.

27. Ying S., Li L., Guo R. Building 3D cadastral system based on 2D survey plans with SketchUp / Geo-Spatial Information Science. 2011. - № 14 (2). - P. 129-136.

28. Сидоренко С.В., Романцов А.Д. Спутниковый мониторинг паводка на реке Томь // Земля из космоса: наиболее эффективные решения. - 2010. - № 6. - С. 70-77.

Поступила 23.11.2018 2.

\section{Информация об авторах}

Аврунев Е.И., кандидат технических наук, доцент кафедры кадастра и территориального планирования Сибирского государственного университета геосистем и технологий.

Гатина H.B., аспирант отделения геологии Инженерной школы природных ресурсов Национального исследовательского Томского политехнического университета.

Козина M.B., старший преподаватель отделения геологии Инженерной школы природных ресурсов Национального исследовательского Томского политехнического университета.

Попов B.K. , доктор геолого-минералогических наук, профессор отделения геологии Инженерной школы природных ресурсов Национального исследовательского Томского политехнического университета. 
UDC 539.186:537; 539.196:537, 332.34:711.144

\title{
3D VISUALIZATION OF ADVERSE NATURAL CONDITIONS FOR ADJUSTMENT OF LAND CADASTRAL VALUE
}

\author{
Evgeny I. Avrunev', \\ avrynevei@ngs.ru \\ Nataliya V. Gatina², \\ www.tusia.0122@mail.ru \\ Mariya V. Kozina ${ }^{2}$, \\ marijamkozina@gmail.com \\ Viktor K. Popov ${ }^{2}$ \\ ' Siberian State University of Geosystems and Technologies, \\ 10, Plakhotny street, Novosibirsk, 630108, Russia. \\ 2 National Research Tomsk Polytechnic University, \\ 30, Lenin Avenue, Tomsk, 634050, Russia.
}

The research is relevant due to the fact that cadastral valuation of land is concerned to be an important part of land plots management. Thus, accuracy and quantity of its results are of great importance for scientific methodological fundamentals of valuation as well as for practice. Being reformed, the system of cadastral valuation of land is not able to provide integration and sharing data from various sources.

The aim of the research is to suggest accounting for adverse geotechnical conditions at cadastral valuation of land with the help of geoinformational analysis and 3D cartographic modeling of flooding within the boundaries of urban land.

The applied methods: theoretical analysis, methods of research, generalization and other established analytical methods, geoinformational analysis, methods of cartographic data visualization, 3D modeling of geospatial data.

Results. On the exemple of Levoberezhye area in Tomsk the authors have carried out the geoinformational analysis on the basis of geotechnical research and spring flood monitoring. The analysis results in outline sketch map of zoning Levoberezhye according to the most favorable hydrological conditions. Specifying the need for the integrated approach to determine the factors of cadastral value, which include the influence of hydrological conditions, resulted in 3D digital modeling of relief and geological constitution of Levoberezhye area. This modeling is able to meet the scientific and practical challenge of accounting for adverse geotechnical conditions of cadastral valuation, keeping the unified state register of immovable property, urban planning and managing territorial entity. Thus the authors proposed the approach to evaluation of negative geotechnical processes and phenomena progressing in urban areas for adjustment of cadastral value.

\section{Key words:}

Cadastral valuation, urban areas, geoinformational analysis, 3D modeling, geotechnical conditions.

\section{REFERENCES}

1. Koshkarev A.V., Ryakhovskiy V.M., Serebryakov V.A. Infrastruktura raspredelennoy sredy khraneniya, poiska i preobrazovaniya prostranstvennykh dannykh [Infrastructure of Distributed Environment of Spatial Data Storage, Search and Processing]. Otkrytoe obrazovanie, 2010, no. 5, pp. 61-73.

2. Ukaz Prezidenta Rossiyskoy Federatsii № 203 ot 09.05 .2017 g. «O Strategii razvitiya informatsionnogo obshchestva $v$ Rossiyskoy Federatsii na 2017-2030 gody» [0n the Strategy for the Development of the Information Society in the Russian Federation for 2017- 2030]. Sobranie zakonodatelstva RF, 2006, no. 35, articles 3775 .

3. Popov V.K., Kozina M.V., Levak Yu.Yu., Shvagrukova E.V. Ecologization of water-land property matters on the territory of the Tom lower course. IOP Conference Series: Earth and Environmental Science, 2016, vol. 33, 012057, 5 p.

4. Popov V.K., Kozina M.V. Ecologization of cadastral valuation of lands for sustainable development of urbanized lands. Bulletin of the Tomsk Polytechnic University. Geo Assets Engineering, 2015, vol. 326, no. 11. pp. 98-105.

5. Strategiya sotsialno-ekonomicheskogo razvitiya Tomskoy oblasti do 2030 goda. Prilozhenie $k$ postanovleniyu Zakonodatelnoy Dumy Tomskoy oblasti ot 26.03.2015 № 2580 [Strategy of social and economic development of Tomsk region till 2030. Application to the order of Legislation Duma of Tomsk region, 26.03.2015 no. 2580]. Available at: http://old.duma.tomsk.ru/ page/29000/ (accessed 15 November 2018).

6. Federalnaya sluzhba po gidrometeorologii i monitoringu okruzhayushchey sredy (Rosgidromet) [Federal service on hydrometeorology and monitoring of environment (Rosgidromet)]. Available at: http://www.meteorf.ru (accessed 15 November 2018).

7. Kozochkina E.A. Sovershenstvovanie metodicheskogo obespecheniya kadastrovoy otsenki obektov nedvizhimosti. Avtoreferat Kand. nauk [Perfection of methodical support of cadastral valuation of real estate objects. Cand. Diss. Abstract]. Novosibirsk, 2018. $24 \mathrm{p}$.

8. Popp E.A. Razrabotka metodiki otsenki vliyaniya ekologicheskoy sostavlyayushchey na kadastrovuyu stoimost zemelnykh uchastkov (na primere goroda Biyska). Avtoreferat Kand. nauk [Development of a methodology for assessing the impact of the environmental component on the cadastral value of land plots (on the example of Biysk). Cand. Diss. Abstract]. Novosibirsk, 2015. $24 \mathrm{p}$.

9. Podryadchikova E.D. Razrabotka metodiki zemelno otsenochnykh rabot na osnove geoinformatsionnogo analiza sotsialno territorialnykh vaaimosvyazey elementov gorodskoy infrastruktury. Avtoreferat Kand. nauk [Development of the methodology of land-valuation work on the basis of geoinformation analysis of socio-ter- 
ritorial interrelations of the elements of urban infrastructure. Cand. Diss. Abstract]. Novosibirsk, 2015. 24 p.

10. Kochetova V.A. Kadastrovaya otsenka gorodskikh zemel na osnove ucheta ekologicheskikh faktorov [Cadastral valuation of urban land based on environmental factors]. Science Time, 2015, no. 12 (24), pp. $422-425$.

11. Avrunev E.I., Chernov A.V., Dubrovsky A.V., Komissarov A.V., Pasechnik E.Yu. Technological aspects of constructing $3 \mathrm{~d}$ model of engineering structures in the cities of the RF arctic region. Bulletin of the Tomsk Polytechnic University. Geo Assets Engineering, 2018, vol. 329, no. 7, pp. 131-137. In Rus.

12. Karpik A.P., Avrunev E.I., Truhanov A.E. To the question of geodetic and cartographic provision of cadastral register. International Journal of Applied Engineering Research, 2015, no. 10 (18), pp. 39601-39602.

13. Oparin V.N., Seredovich V.A., Yushkin V.F., Ivanov A.V., Prokopeva S.A. Application of laser scanning for developing a 3D digital model of an open-pit side surface. Journal of Mining Science, 2007, no. 43 (58), pp. 545-554.

14. Ying S., Guo R., Li L. Implementation of 3D cadastre with 3DGIS: Practices and challenges. Journal of Geomatics, 2018, no. 43 (2), pp. 1-6.

15. Olkhovatenko V.E., Rutman M.G., Lazarev V.M. Opasnye prirodnye i tekhnoprirodnye protsessy na territorii g. Tomska i ikh vliyanie na ustoychivost prirodno-tekhnicheskikh sistem [Natural and technonatural hazardous processes in the city of Tomsk and their influence on the strength of natural and technical systems]. Tomsk, Pechatnaya Manufaktura Publ., 2005. 151 p.

16. Strokova L.A. Inzhenerno-geologicheskoe rayonirovanie territorii Tomskogo Priobya po stepeni ustoychivosti geologicheskoy sredy $k$ tekhnogennoy nagruzke. Avtoreferat Dis. Kand. nauk [Engineering-geological zoning of the Tomsk $\mathrm{Ob}$ area in terms of the degree of stability of the geological environment to the technogenic load. Cand. Diss.]. Tomsk, 1997. 20 p.

17. Popov V.K., Lukashevich O.D., Korobkin V.A. Ekologo-ekonomicheskie aspekty ekspluatatsii podzemnykh vod Ob-Tomskogo mezhdurechya [Ecological and economic aspects of exploring groundwaters of $\mathrm{Ob}$-Tom interfluve]. Tomsk, TGASU Publ., $2003.174 \mathrm{p}$.

18. Savichev 0.G. Spatial patterns of the evolution of the chemical composition and discharge of river water in the $0 \mathrm{~b}$ River basin. Doklady Earth Sciences, 2016, vol. 466, pp. 59-63.

19. Dutova E.M. Hydrogenous mineral neoformations in Tomsk water intake facility from underground sources. IOP Conference Se- ries: Earth and Environmental Science, 2016, vol. 33 Contemporary Issues of Hydrogeology, Engineering Geology and Hydrogeoecology in Eurasia, 012017, 6 p.

20. Leonova A.V. Geotechnical properties of gullying in Tomsk Oblast. IOP Conference Series: Earth and Environmental Science, 2016, vol. 43 Problems of Geology and Subsurface Development, 012037, 4 p.

21. Pokrovskiy V.D. Information retrieval system of underflooding estimation in Tomsk. Vestnik TSUAB, 2015, no. 1 (48), pp. 172-181. In Rus.

22. Avrunev E.I., Kozina M.V., Popov V.K. Investigation of the cost factors of land in urbanized areas. Vestnik Siberian State University of Geosystems and Technologies, 2018, no. 2 (23), pp. 130-143. In Rus.

23. Karpik A.P., Khoroshilov V.S. Sushchnost geoinformatsionnogo prostranstva territorii kak edinoy osnovy razvitiya gosudarstvennogo kadastra nedvizhimosti [The essence of the geoinformation space of the territories as a unified basis for the development of the state real estate cadastre]. Izvestriya vuzov. Geodeziya i aerofotosemka, 2012, no 2/1. pp. 134-136.

24. Popp E.A. The possibilities of GIS and mapping methods for analysis of ecological state of territorial entities [Proceedings of the International Conference: Innovations and GIS-technologies for the Development of Territories]. Sbornik materialov mezhdunarodnoy konferencii. Innovatsii $i$ GIS tekhnologii dlya razvitiya territoriy [Proc. of the conference. Innovations and GIS for territory development]. Ust-Kamenogorsk, VKGTU Publ., 2014. pp. $67-74$.

25. Karpik A.P., Musikhin I.A. Research and practical trends in geospatial sciences. International Archives of the Photogrammetry, Remote Sensing and Spatial Information, 2016, no. 41, pp. 177-184.

26. Ledoux H., Meijers M. Topologically consistent 3D city models obtained by extrusion. International Journal of Geographical Information Science, 2011, no. 25 (4), pp. 557-574.

27. Ying S., Li L., Guo R. Building 3D cadastral system based on 2D survey plans with SketchUp. Geo-Spatial Information Science, 2011, no. 14 (2), pp. 129-136.

28. Sidorenko S.V., Romanczov A.D. Satellite monitoring of floods on the Tom River. Earth from space: the most effective solutions, 2010, no. 6, pp. 70-77. In Rus.

Received: 23 November 2018.

\section{Information about the authors}

Evgeny I. Avrunev, Cand. Sc., associate professor, Siberian State University of Geosystems and Technologies.

Nataliya V. Gatina, postgraduate, National Research Tomsk Polytechnic University.

Mariya V. Kozina, senior lecturer, National Research Tomsk Polytechnic University.

Viktor K. Popov, Dr. Sc., professor, National Research Tomsk Polytechnic University. 